\title{
水文統計に用いられる分布の 右裾点の推定に関する一考察
}

\author{
A CONSIDERATION ON RIGHT TAIL POINT ESTIMATION FOR THE \\ DISTRIBUTIONS IN HYDROLOGICAL STATISTICS
}

\author{
廣瀬 英雄 $^{1}$ \\ Hideo HIROSE

\begin{abstract}
${ }^{1}$ 正会員 工博 九州工業大学情報工学部教授（T820-8502 福岡県飯塚市大字川津680-4）
\end{abstract}
\begin{abstract}
This paper describes an upper tail point estimation method using the incomplete data by the maximum likelihood estimation method. In some data cases, it happens to occur that the estimates for upper tail points such as 100-year return period can be smaller than the observed maximum annual flood datum, even if the number of observed data is smaller than 100; this result of analysis cannot be acceptable from the practioners' viewpoint. Because, adopting such estimates in hydrologic frequency analysis may cause dangerous designs and plans for flood prevention. By weighting much to data in upper tail probability portion, such a phenomenon may be reduced. Peaks over threshold method (POT) and probability weighted moment method (PWM) are included in such weighting methods. This paper deals with a weighting method by using incomplete data. An example for St. Mary's River data shows the superior points in such a treatment.
\end{abstract}

Key Words: Upper tail point estimation, Gamma distribution, Incomplete data, Extended KolmogorovSmirnov statistic, Parametric bootstrap, Delta method

\section{1. まえがき}

洪水災害に耐える水工構造物の設計や計画は，対 象とする事象に関する変量の極值を想定して行う必 要があり, 水文統計で用いられる確率分布の推定に 関しては，分布の右裾点（確率水文量）の推定値と その推定精度が重要となる.また, 洪水災害を予防す る観点からは，推定は安全側に行うことが望ましい。 この二つの観点から右裾点の推定に関して考察を 行った.

従来, 水文統計学では，実在する河川の観測データ に対して, 種々の確率分布 (対数正規, Gumbel, 代ン マ, 対数ガンマ, 一般化極值（GEV）分布など）を あてはめ, 適当と思われる分布を何らかの方法（例 えば, 尤度, 最小2乗法, Kolmogorov-Smirnov検定
（K-S検定），SLSC（standard least-squares criterion）1)など）で特定して, 確率水文量の推定を 行ってきた. このときのデータとしては, ある地点で の年間流水最大量がよく用いられてきた ${ }^{22}$.

最近では推定精度を上げるため，過去に記録され た洪水の記録を付加することも行われている3,4).こ れは過去に大きな洪水が起こった情報を何とかデー 夕解析に組み込んで解析の精度を上げようとする試 みであり，分布の右裾の情報を付加しようとしてい ることになる.

また，洪水とはみなせないような小さな量を持つ データの影響を少なくするため, 毎年の最大流量で はなくあるしきい值越えるデータ（POT：peaksover-threshold）を採用して確率分布のパラメータ の推定を行ったり, PDS（partial duration series） 
デー夕を用いることも始められており,これには一般 化パレート分布へのあてはめがよく行われている5 . このことは右裾に近いデータをより多くとることで 右裾点の推定精度を上げようとの試みの一つと考え られる。

さて, 文献によると6),7), Gumbel分布については最 尤推定法が，G E V 分布についてはP W M 法? （probability weighted moment法）が, 確率水文 量の推定精度の観点からはよいとされている. GEV 分布においても, 分布のパラメー夕推定に関しては 最尤推定法の優位性が示されているものの，ここで 注目すべきことは, PWM法もまた分布のデー夕に関 して重夕付けを行うことで，推定したい統計量の推 定精度を上げることに寄与している点である，刎論， 推定そのものの安定性に関して最尤推定法より優位 であることもPW M 法の利用価值として挙げられる. このことは, POTデータの採用と同じく, 分布の右裾 点のデー夕の強調法の一つと考えられる.

本稿では, このような観点に基づき, 分布の右裾を 強調する基本的な方法として,右側分布には完全デー 夕を使い，その他には不完全デー夕を使った場合の， 分布の右裾点の推定値の妥当性と推定精度について 考察した結果を述べる.

\section{2. 完全データのみの場合の問題点}

毎年最大流量のデータが過去何年かにわたって蓄 積されているとする.例えば,ここではSt Mary'sの過 去72年間のデー夕2)を考える. 推定したい確率水文量 を 100 年に一度の年最大流量 $\left(x_{.99}\right.$ と表す) とする.こ のとき, 最尤推定法で推定された $x_{.99}$ の値とその $90 \%$ 信頼区間は, 表-1のとおりとなっている. 表で*印は Kite(1988)の再掲であるが, **印は著者が計算した もので，信頼区間はbootstrap手法8）（parametric bootstrap）を用いて求めた值である. Fisherの情報 行列をもとに, デル夕法9) から直接解析的に近似 $90 \%$ 信頼区間を求めることも可能であるが，対数正規分 布に関しては少し異なったものの，ガンマ分布に関 しては両者はほとんど同じ值を示したので，ここで はbootstrapの結果の夕を示している.

元のデータの最大值は1971年の8月に観測された $974 \mathrm{~m}^{3} / \mathrm{s}$ である. 表-1によると, 3 パラメータ分布の 中で対数尤度の最も大きくなるガンマ分布はこの值 を $90 \%$ 信頼区間の中に含んでいない. 年最大流量を確 率変数と仮定し，観測されたデー夕の背後には真の 分布があってパラメータ推定はその真の分布に近い ものを推定するという立場に立てば, 974という数は
表-1 $x_{99}$ の最尤推定値とその信頼度（完全デー夕）

\begin{tabular}{|c|c|c|c|c|}
\hline & $\begin{array}{c}\text { 推定 } \\
\text { 值 }^{*}\end{array}$ & $\begin{array}{c}\text { 推定 } \\
\text { 誤差 }^{*}\end{array}$ & $\begin{array}{c}90 \% \\
\text { 信頼区間** }\end{array}$ & $\begin{array}{c}\text { 対数 } \\
\text { 尤度 }^{* *}\end{array}$ \\
\hline 対数正規 & 882 & 93.1 & - & -451.363 \\
\hline Gumbel & 848 & 51.6 & - & -451.597 \\
\hline ガンマ & 855 & 68.4 & 734,973 & -451.223 \\
\hline 対数ガンマ & 879 & 101.0 & 765,998 & -451.407 \\
\hline
\end{tabular}

*: Kite (1988); **: 廣瀬 ; 推定はともに最尤推定法

表-2 $974 \mathrm{~m}^{3} / \mathrm{s}$ に対する再現期間（完全デー夕）

\begin{tabular}{|c|c|}
\hline & 再現期間 \\
\hline 対数正規 & 221 \\
\hline Gumbel & 319 \\
\hline ガンマ & 302 \\
\hline 対数ガンマ & 213 \\
\hline
\end{tabular}

たまたま出現した変量であり, 90\%信頼区間に入ら ないことも不合理ではない，という見方もできる，し かしながら, 真の分布というものはもともと存在せ ず,それは便宜的に使うものであって, 実際にあるの はその河川に特有なデータのタであるという立場に 立てば, 推定された $90 \%$ 信頼区間に観測された最大 值（最も重要なデータ）が含まれていないというの は問題である. 河川計画で100年に一度の災害を想定 しようとしているのに, 72年の間に実際に観測され た值が軽視されているのは（極值を求めようとする 立場からは）危険側に推定されていることになり不 合理なことである.ただし, 通常, 水文統計での信頼 区間には95\%信頼区間が使われるが,ここでは $x_{.99}$ の $90 \%$ 程度の信頼区間でも不都合が起こることを示 すために $90 \%$ 信頼区間を用いている.

また, 流量 $974 \mathrm{~m}^{3} / \mathrm{s}$ 対応する再現期間を上の 4 つの分布に対して求めた結果を表-2に示す. 72 年間 の間に実際に観測された流量に対する再現期間は Gumbel, ガンマ分布で特に大きく, それぞれ319, 302年となっている. 比較的裾の長い対数正規分布で さえも221年とふなり長い.このことからも推定は危 険側に行われていることが分かる.

これらのことは, 72 年間の全てのデータを同じ重 みで取り扱ったことにも起因すると考えられる.一 方, 分布の右裾を重要視すれば, 右裾の推定に関して は大きく危険側に推定を行うことは少ないと思われ る.そこで,ここでは最も基本的な方法の一つと考え られる, 分布の右裾を完全データとして, その他を不 
完全データとして扱った場合の推定について考察す ることにする.

$974 \mathrm{~m}^{3} / \mathrm{s}$ という流量がoutlierであれば, このよう な検討は無意味であるが, 文献(10)に記載されてい る異常值検定の結果からは $974 \mathrm{~m}^{3} / \mathrm{s}$ は棄却されない ことを付記する。

\section{3. 完全データと不完全データの併用}

観測されたデータ（ここでは毎年最大量でも非毎 年データでもよいとする）を大きい順に並べ直した ものを, $x_{1}, x_{2}, \ldots, x_{k-1}, x_{k}, x_{k+1}, \ldots, x_{n}$ とする. 観測デー夕の大きい $k$ 個の値 $\left(x_{1}, x_{2}, \ldots, x_{k}\right)$ に対 しては完全データとして使い, それ以外のデータ $\left(x_{k+1}, \ldots, x_{n}\right)$ に対しては不完全データとして使っ て, 尤度関数を次のように表す。

$$
L_{k}=\left(F\left(x_{k}\right)\right)^{n-k} \prod_{i=1}^{k} f\left(x_{i}\right)
$$

ここに, $f(x), F(x)$ はそれぞれ確率分布の密度関数 と分布関数である. 観測データの大きいものはその まま情報を残し，小さい方に関してはデー夕は $x_{k}$ 以 下であるという情報しか用いていない。 このように 尤度関数を作ると, 情報量は減るので分布全体とし ては推定精度は一般に悪くなる.しかしながら, 後で 示すように，分布の右裾点に関してより合理的な推 定値が得られる場合がある. パラメー夕は最尤推定 法を用いて推定する.

\section{St. Mary's Riverデータによる解析例}

ここでは, St Mary's Riverデータ²に関して, 尤度 の最も大きかった分布（ガンマ分布）がこのデータ には適合していると仮定して，刃゙ンマ分布を用いて 検討を行ってみた. ガンマ分布の密度関数を，

$f(x ; \alpha, \beta, \gamma)=\frac{1}{\gamma \Gamma(\beta)}\left(\frac{x-\alpha}{\gamma}\right)^{\beta-1} \exp \left[-\left(\frac{x-\alpha}{\gamma}\right)\right]$

$$
(x \geq \alpha, \beta>0, \gamma>0)
$$

で定義する.（1)式での完全データの個数 $k$ をここで は, 全デー夕数の半数 36 , その $2 / 3$ の 24 , その半数の 12 , その $2 / 3$ のにとり, それらに対応する推定值と 信頼度について調べてみた.

最尤推定法を用いて求めた(1)式に対する $x_{.99}$ の推 定值とその $90 \%, 95 \%$ 信頼区間を表-3に示す.
表-3 $x_{.99}$ の推定值とその信頼度（不完全データ）

\begin{tabular}{|c|c|c|c|}
\hline$k$ & $\begin{array}{c}x_{.99} \text { の推 } \\
\text { 定値 }\end{array}$ & $\begin{array}{c}x_{99} \text { の } \\
90 \% \text { 信頼区間 }\end{array}$ & $\begin{array}{c}x_{99} \text { の } \\
95 \% \text { 信頼区間 }\end{array}$ \\
\hline 8 & 915 & 555,1275 & 486,1343 \\
\hline 12 & 896 & 604,1187 & 548,1243 \\
\hline 34 & 854 & 703,1006 & 674,1035 \\
\hline 36 & 853 & 721,995 & 684,1022 \\
\hline
\end{tabular}

（推定法は最尤推定法）

表- 1 によると, 完全データのときのガンマ分布の $x_{.99}$ の推定値は8 55 となり観測されたデー夕の最大 值に比べてかなり小さいが，不完全デー夕併用した $k=8$ のときそれは 915 と大きくなり安全側に推定さ れている.ただし，推定値の信頼区間は（情報量が少 ないため）大きくなる。

経験分布と推定された分布関数とがどの程度適合 しているかについては，注目すべき分布の右裾で測 るのが妥当であるので,ここでは, $x_{k}$ から上側につい て分布の距離の最大值 $D e_{k}^{k}, D e_{k}^{0}, D c_{k}^{k}, D c_{k}^{0}$ を調べ た.ここに,

$$
\begin{aligned}
& D e_{k}^{k}=\max _{x_{1} \geq x>x_{k}}\left|F(x)^{k}-F_{e}(x)\right| \\
& D e_{k}^{0}=\max _{x_{1} \geq x>x_{k}}\left|F(x)^{0}-F_{e}(x)\right| \\
& D c_{k}^{k}=\max _{x_{1} \geq x>x_{k}}\left|F(x)^{k}-F_{c}(x)\right| \\
& D c_{k}^{0}=\max _{x_{1} \geq x>x_{k}}\left|F(x)^{0}-F_{c}(x)\right|
\end{aligned}
$$

で定義する.また, $F(x)^{k}$ は不完全デー夕を含む(1)式 から推定された分布関数, $F(x)^{0}$ は完全デー夕のみ を用いて推定された分布関数, $F_{e}(x), F_{c}(x)$ は分布 関数,

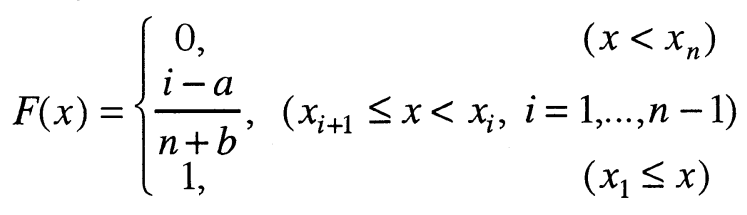
で,

$$
\begin{array}{lll}
a=0, & b=0 & \left(F(x)=F_{e}(x)\right) \\
a=0.4, b=0.2 & \left(F(x)=F_{c}(x)\right)
\end{array}
$$

とするとき, $F_{e}(x)$ は経験分布関数, $\quad F_{c}(x)$ は Cunanne ${ }^{11)}$ のプロッティングポジションを用いた分 布関数となる. $D e_{k}^{k}, D e_{k}^{0}$ はKolmogorov-Smirnov 統計量の拡張になっているので, これをここでは, 拡 張K-S統計量と呼ぶ. 


\begin{tabular}{|c|c|c|c|c|}
\multicolumn{1}{|c|}{ 表-4 $D e_{k}^{k}, D e_{k}^{0}, D c_{k}^{k}, D c_{k}^{0}$} \\
\hline$k$ & $D e_{k}{ }^{k}$ & $D e_{k}{ }^{0}$ & $D c_{k}{ }^{k}$ & $D c_{k}{ }^{0}$ \\
\hline 8 & 0.0157 & 0.0457 & 0.0239 & 0.0375 \\
\hline 12 & 0.0272 & 0.0457 & 0.0351 & 0.0375 \\
\hline 24 & 0.0481 & 0.0489 & 0.0556 & 0.0565 \\
\hline 36 & 0.0497 & 0.0502 & 0.0572 & 0.0565 \\
\hline
\end{tabular}

表-4に, $k=8$ のときの $D e_{k}^{k}, D c_{k}^{k}$ の値，および $D e_{k}^{0}, D c_{k}^{0}$ の値を示す. 表から特に $D e_{k}^{k}$ が優れてい ることが分かる.この結果を表-2の推定值と併せて 考えると，特に安全側に設計したい場合に有効であ ると思われる。

図1-4には， $k=8$ のときに対して, 推定された分 布, および $x_{p}$ （ $x_{p}$ 以上の洪水の発生する確率を $p$ と する）の $90 \%, 95 \%$ 信頼区間を, 経験分布関数および Cunanneのプロッティングポジションを用いた分布 関数と併記して示した. 分布の右裾において推定さ れた分布は $k=8$ のときは経験分布の近くを通って いる様子が分かる. $1 / 72=0.0139$ であることを考え ると, $k=8$ のときでの $D e_{k}^{k}, D e_{k}^{0}$ の值から, 推定さ れた分布がどの程度経験分布に近いかが分かる。 Cunanneのプロッティングポジションに対応する $D c_{k}^{k}$ は $e_{k}^{k}$ に比べて悪くなっている.

\section{5. まとめ}

水文統計に用いられる確率分布の推定にあたって は，分布の右裾の推定値とその信頼度が重要になる。 従って, 右裾に近い部分のデー夕に重みを付け，その 他の部分を軽視ずることで，分布の右裾点の推定精 度を上げることができる可能性がある. Historical dataの採用, POTによるデー夕の収集, PWMによる 確率分布への重み付けを行った後でモーメント法に よる推定を行う方法なども, この類と考えられる. 本 稿では, この重み付けを, 最も素直な形の一つである 不完全デー夕を用いて検討を行った. ここで提案し ている拡張K-S統計量の基準を用いてST. Mary's Riverの推定分布の比較を行った結果, 分布の右裾点 の推定に関しては経験分布を忠実に反映することが 分かった. また，推定值の信頼度については，失われ た情報の分だけ悪くなってはいるが，これは安全側 の設計に寄与すると考えることもできる．他の方法 と併せて欠点を補えばよいであろう。本研究での最 も重要な成果は, 従来の方法では 100 年を下回る年最 大流量デー夕の最大值が10 0 年確率水文量の推定值 よりも大きく推定されることが起こっていたが,こ

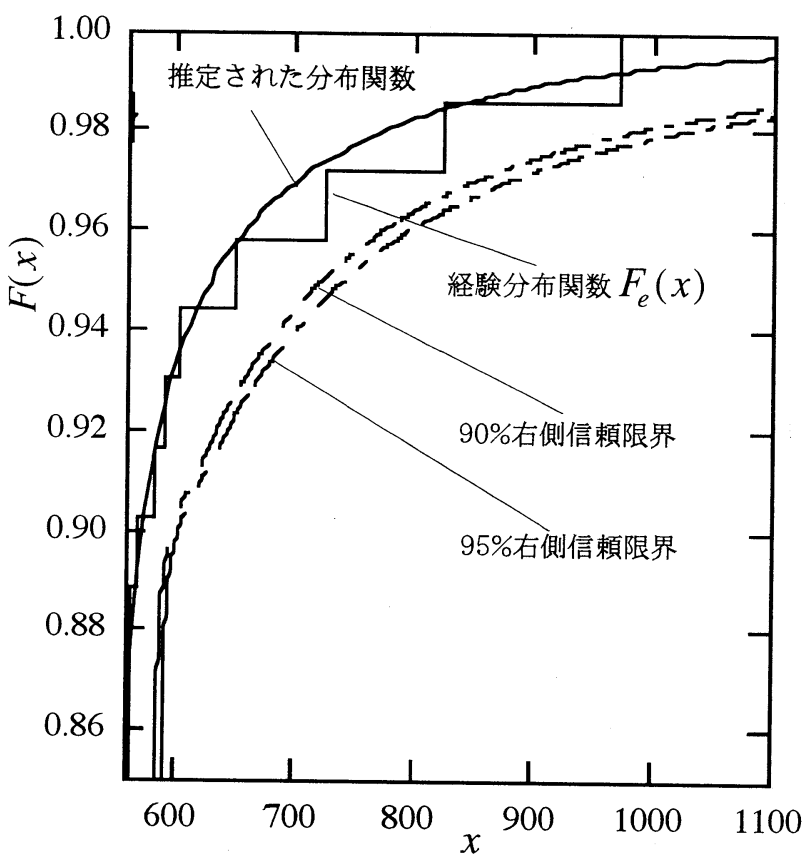

図-1 推定された分布, および $x_{p}$ の $90,95 \%$ 信頼区間と

$$
F_{e}(x) \text { との比較 }(k=8)
$$

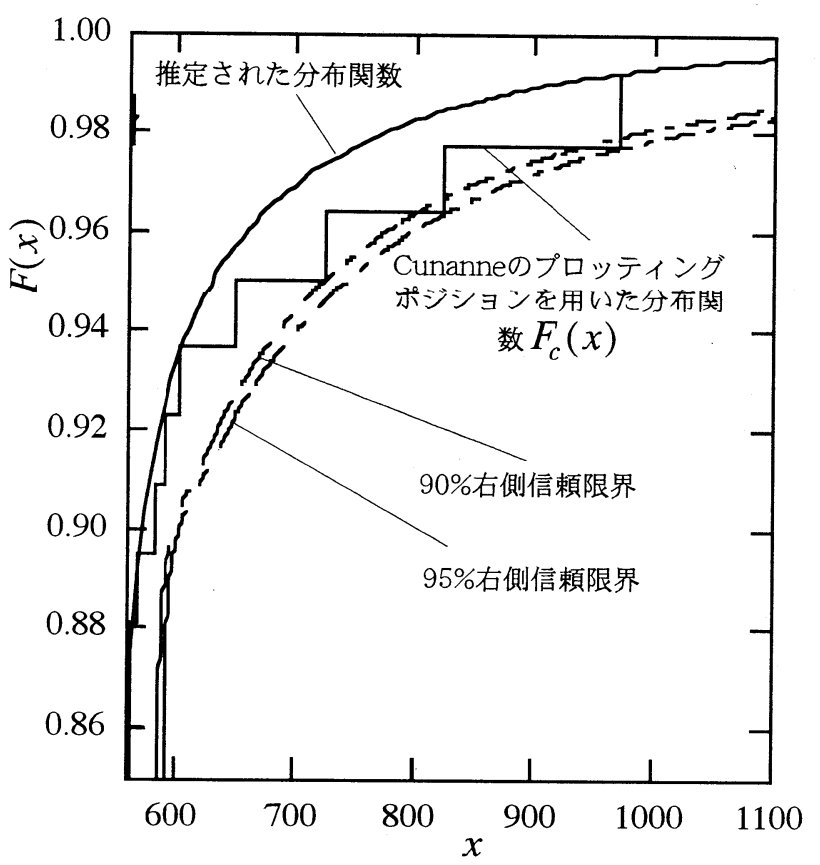

図-2 推定された分布, および $x_{p}$ の90, 95\%信頼区間と

$$
F_{c}(x) \text { との比較 }(k=8)
$$




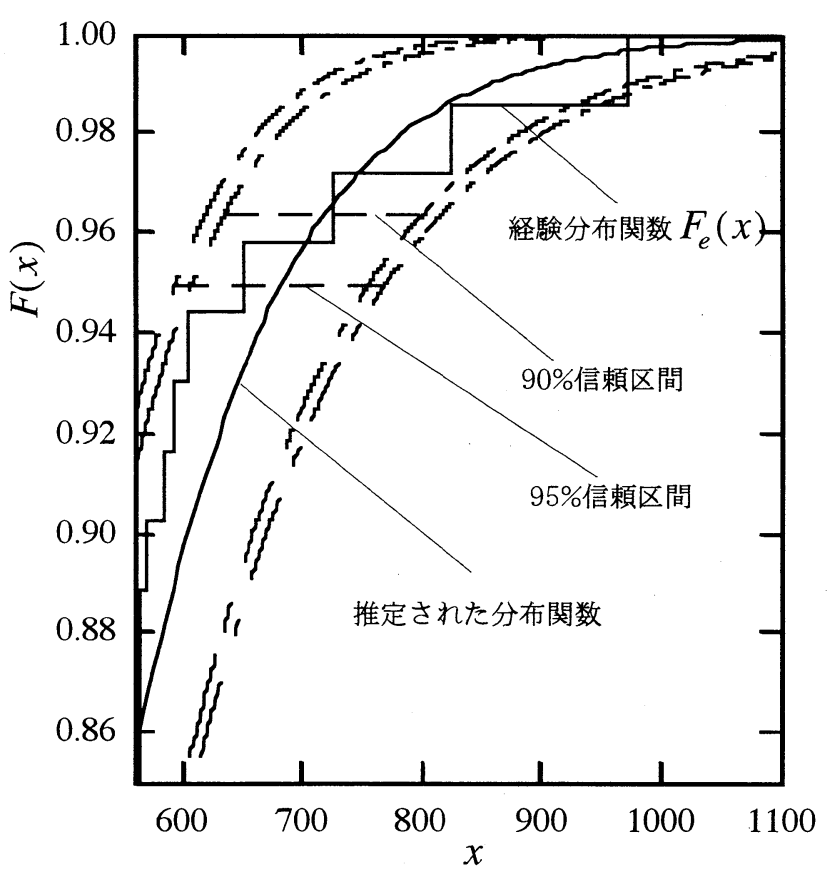

図-3 推定された分布, および $x_{p}$ の $90,95 \%$ 信頼区間と $F_{e}(x)$ との比較 $(k=0)$

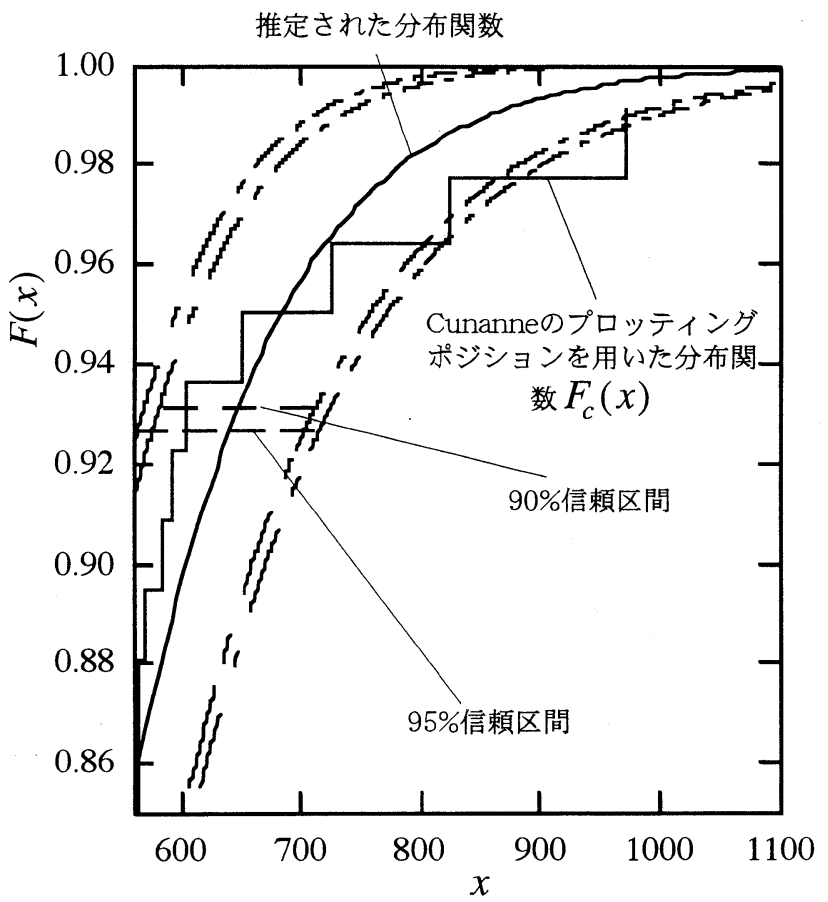

図-4 推定された分布, および $x_{p}$ の $90,95 \%$ 信頼区間と

$$
F_{c}(x) \text { との比較 }(k=0)
$$

こでの方法では最大值を反映した形で推定されてい ることである.

一般的な確率分布に対して適用できる統計的な性 質を特定の河川の極值解析に適用する場合には，そ の河川の特徵を重要視する必要がある. 特に, 過去に わたっての最大流量があたかもはずれ值（outlier） のように見えるときにはその值に特別の注意を払う 必要がある. 分布の右裾の部分を強調する解析はこ のことに配慮したものである. 最近, POTなどの手法 が用いられ始めているが，POTの情報に更に不完全 デー夕を付加することも考えられる. その場合, 更に 推定精度がよくなると考えられる。

ここで解析したデータの種類と検討を行った確率 分布は少ないが，上に述べた傾向は他の分布にも一 般的に類推できるものである. 今後, 他の分布や他の 河川デー夕についても検討を加えていきたい.

なお、分布の右裾にあたる点の数 $k$ をどの程度に するのが適当であるかの検討は今回行っていない. 今後の課題である.

謝辞 : 京都大学防琰研究所の宝教授には文献を紹介 していただいた.ここに謝意を表する.

\section{参考文献}

1）高棹, 宝, 清水 : 琵琶湖流域水文デー夕の基礎的分析, 京都大学防災研究所年報, 29, B-2, pp.157-171 (1986)

2) Kite, G.W. : Frequency and Risk Analysis in Hydrology, Water Resources Publications, Fort Collins, Colorado, USA (1988)

3) Hosking, J.R.M., Wallis : The value of historical data in flood frequency analysis, Water Resources Research, 22, pp.1606-1612 (1986)

4) Stedinger, J.R, Cohn T.A. : Flood frequency analysis with historical and paleoflood information, Water Resources Research, 22, pp.785-793 (1986)

5) 宝 : 水文頻度解析の進歩と将来展望, 水文 - 水資源学会 誌, 11,pp.740-756 (1998)

6) 宝, 高棹 : 水文頻度解析モデルの母数推定法の比較評価 水工学論文集, 土木学会, 34,pp.7-12 (1990)

7) Hosking, J.R.M., Wallis, J.R., Wood, E.F. : Estimation of the generalizerd extreme-value distribution by the method of probability weighted moments,

Technometrics, 27, pp.251-261 (1985)

8) Efron, B. : Bootstrap methods: another look at the jackknife, Ann. Statist., 7, 1-26 (1979)

9) Rice, J.A. : Mathematical Statistics and Data Analysis, Wadsworth and Brooks/Cole (1988)

10）水文・水資源ハンドブック, 水文・水資源学会編 (朝倉）（1998）

11) Cunanne, C. : Unbiased plotting position - a review, Journal of Hydrology 37, pp.205-222 (1978) 